\title{
Chapter 7 \\ (Micro)evolutionary Changes and the Evolutionary Potential of Bird Migration
}

\author{
Miriam Liedvogel and Kira Delmore
}

\begin{abstract}
Seasonal migration is the yearly long-distance movement of individuals between their breeding and wintering grounds. Individuals from nearly every animal group exhibit this behavior, but probably the most iconic migration is carried out by birds, from the classic V-shape formation of geese on migration to the amazing nonstop long-distance flights undertaken by Arctic Terns Sterna paradisaea. In this chapter, we discuss how seasonal migration has shaped the field of evolution. First, this behavior is known to turn on and off quite rapidly, but controversy remains concerning where this behavior first evolved geographically and whether the ancestral state was sedentary or migratory (Fig. 7.1d, e). We review recent work using new analytical techniques to provide insight into this topic. Second, it is widely accepted that there is a large genetic basis to this trait, especially in groups like songbirds that migrate alone and at night precluding any opportunity for learning. Key hypotheses on this topic include shared genetic variation used by different populations to migrate and only few genes being involved in its control. We summarize recent work using new techniques for both phenotype and genotype characterization to evaluate and challenge these hypotheses. Finally, one topic that has received less attention is the role these differences in migratory phenotype could play in the process of speciation. Specifically, many populations breed next to one another but take drastically different routes on migration (Fig. 7.2). This difference could play an important role in reducing gene flow between populations, but our inability to track most birds on migration has so far precluded evaluations of this hypothesis. The advent of new tracking techniques means we can track many more birds with increasing accuracy on migration, and this work has provided important insight into migration's role in speciation that we will review here.
\end{abstract}

Keywords Migratory traits · Orientation - Evolution - Selection · Candidate gene · High-throughput sequencing $\cdot$ Behavioral genomics

Both the authors contributed equally to this chapter.

M. Liedvogel $(\bowtie) \cdot K$. Delmore

MPRG Behavioral Genomics, Max Planck Institute for Evolutionary Biology, Plön, Germany

e-mail: liedvogel@evolbio.mpg.de 

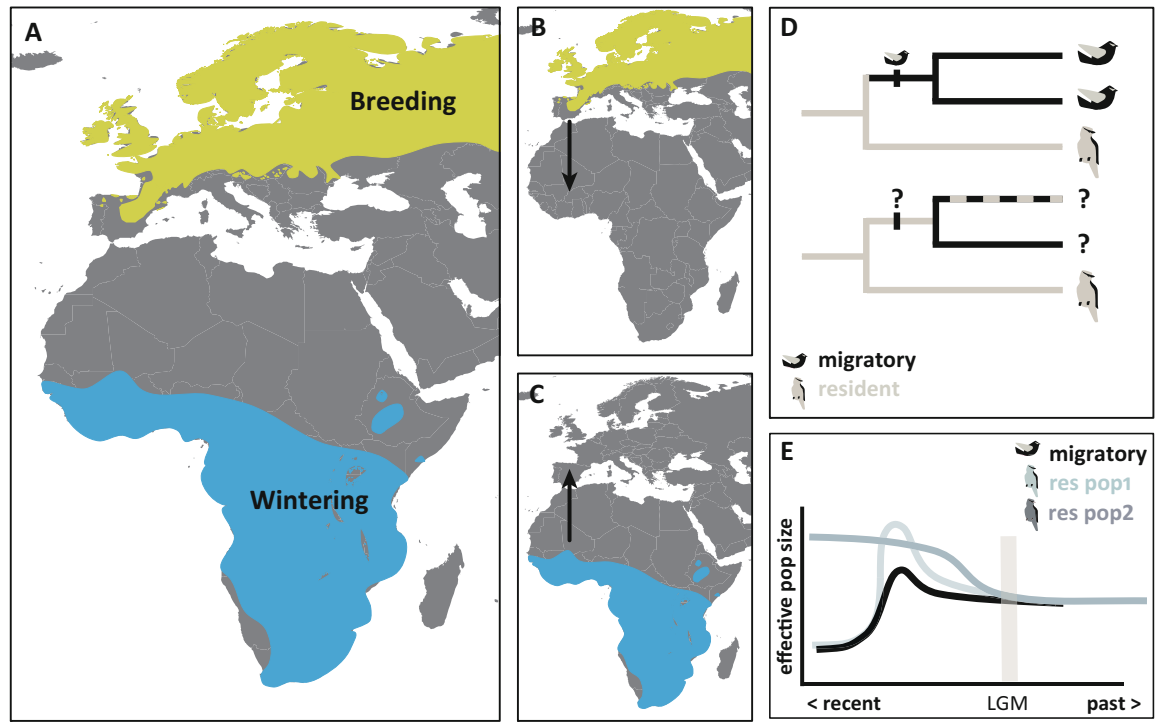

Fig. 7.1 Evolution of migratory and geographic ancestry. (a) Breeding and wintering ranges of a European migratory species. These geographical ranges may have evolved by either (b) a shift of the breeding range from higher latitudes to regions further south (northern-home hypothesis) or (c) a shift of breeding range to grounds further north in order to benefit from richer resources during the breeding season (southern-home hypothesis). Many European species (e.g., songbirds in genera Sylvia, Saxicola, Phylloscopus) are known to come from a speciation core placed around the Himalayan area, favoring the northern-home hypothesis—at least for Eurasian species. (d) Possible scenarios reconstructing the migratory phenotype: inherited from one common ancestor (upper panel) or through (one or multiple) gains and losses of migratory phenotype since a last shared common ancestor (lower panel). The latter scenario makes reconstruction of the migratory phenotype and estimates of phenotype transitions more difficult (redrawn after Zink 2011). (e) Highthroughput genome sequencing data allow inferring demographic history like historical population sizes and divergence times (effective population size by time). This hypothetical demographic scenario summarizes patterns for effective population sizes of different populations; populations start to diverge after last glacial maximum (LGM, 20,000 years ago, indicated by range in gray). In this hypothetical scenario, the migratory population (migratory, in black) is ancestral, and two independent transitions to residence occur (res pop1 and res pop2 in gray), forming independently derived lineages. All three diverging populations show an increase in effective population size after divergence with population sizes of the migratory and resident population 1 dropping subsequently. This sketch for this hypothetical scenario of a migratory bird system leans on the monarch butterfly as one example illustrating how the availability of high-throughput sequencing data can rewrite our understanding of demographic events (see Zhan et al. 2014)

Migration is a fascinating phenomenon that takes place on a global scale and involves individuals from nearly all continents and throughout the animal kingdom. It is long accepted that, within birds, migration evolved in an early ancestor and now the machinery is present in all groups (e.g., Rappole 1995; Berthold 1999). This behavioral phenotype is particularly prominent and equally diverse in birds, ranging 

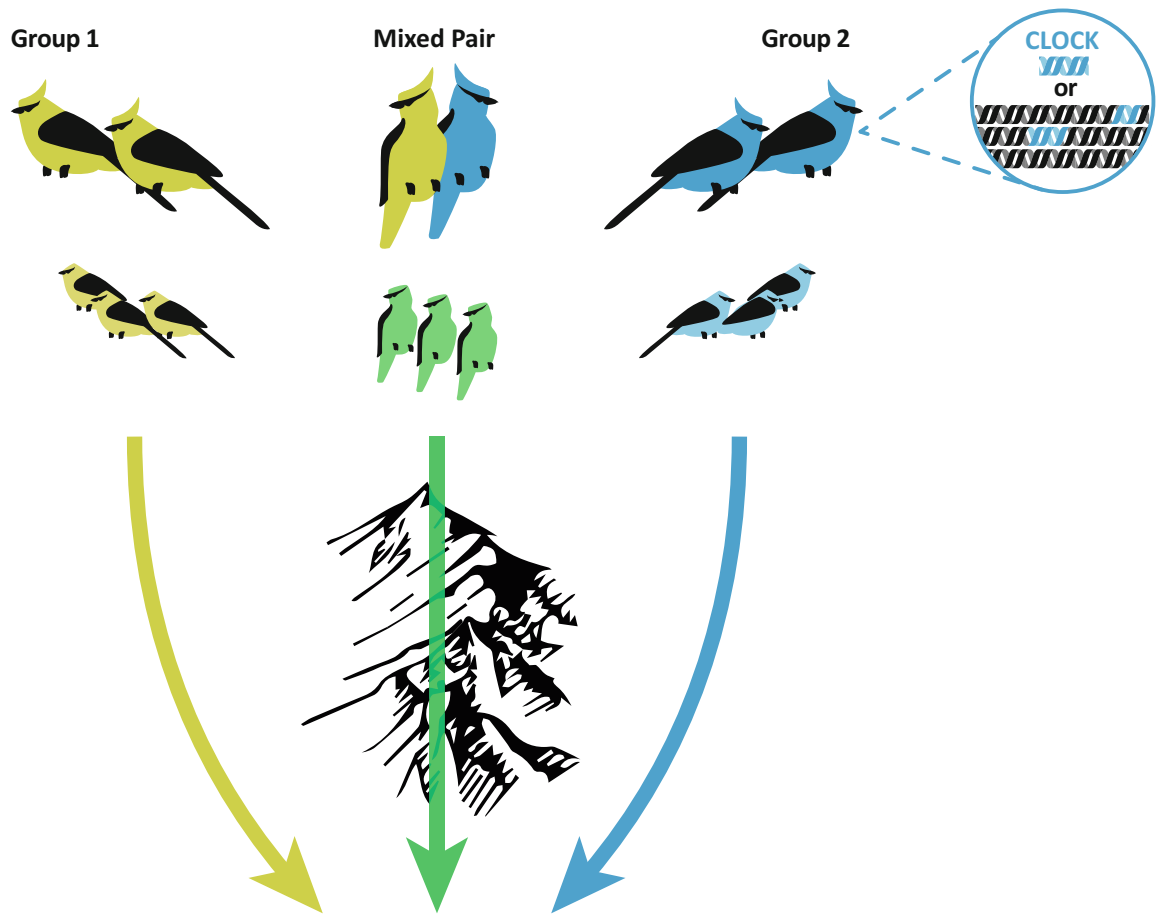

Fig. 7.2 Migratory phenotypes across divides and underlying genetic architecture of orientation. Migratory divides are natural scenarios where birds from two neighboring groups (these groups can be of different species, subspecies, or populations) with different migratory orientation meet and probably hybridize. Offspring of the same parental phenotype (phenotype reflected by color) follow the same migratory orientation phenotype as their parents (i.e., matching colors), usually optimized to lead them around ecological barriers. Offspring of mixed pairs have been shown to use an intermediate phenotype (mirrored as intermediate-color birds with intermediate heading) resulting in migratory routes that may lead them over significant barriers such as mountain ranges, oceans, or wide stretches of desert that a bird has to cross in nonstop flight. Migratory routes are depicted as arrows, coloration coding for differences in migratory phenotype. Attempts to characterize the underlying genomic architecture modulating this phenotypic difference have looked at different scales (here depicted for group 2 as circular inlay): Marker-based approaches focus on preselected candidate genes (exemplified for Clock here) and look for correlation between genetic variation at the marker region and individual phenotype. The advent of high-throughput sequencing data is currently allowing us to expand from marker-based approaches to the entire genome and no longer limits our analyses to restricted regions (depicted for group 2 in blue within genome-wide DNA in black) of the genome

from starlings flocking in impressive formations through the iconic pole-to-pole journeys of Arctic Terns Sterna paradisaea to the almost invisible movement of tiny passerine birds migrating at night completely on their own. These impressive journeys amaze laymen and professional scientists alike, and researchers across numerous disciplines have been studying various aspects of this phenomenon from 
different angles for decades. We will focus on the field of evolution here, highlighting areas that have seen a lot of recent work.

\subsection{History and Geographic Origins}

In this section, we focus on where migration came from, its origins or evolution. The actual ability to migrate likely existed before birds originated or has at least been present since early in their history. Thus, here we define "evolution" in the sense of modification and maintenance rather than the first appearance of a migratory trait/ phenotype in evolutionary history per se, similar to the definition formulated in Zink (2002). This behavior is now extremely labile, turning on and off quickly. Specifically, populations changing their behavior from migratory or sedentary probably do this as a consequence of current ecological conditions (e.g., Alerstam et al. 2003; Salewski and Bruderer 2007). One textbook example here is the Eurasian Blackcap Sylvia atricapilla, a very common breeding bird in Europe with different populations exhibiting the entire range of migratory phenotypes, from sedentary to long-distance migrants and including populations across migratory divides that follow different migratory routes (e.g., southwest from Germany to Spain and Portugal or southeast from Germany to northeastern Africa; Fig. 7.2). Most fascinating in this context is the recent observation that some birds breeding in Germany have started migrating northwest to winter in the UK. This observation comes from the 1960s (Berthold et al. 1992; Rolshausen et al. 2009) and may be in response to an increasing number of bird feeders in the UK providing a great resource for overwintering Blackcaps (Plummer et al. 2015). In addition to within-species variation in migratory phenotype in the Blackcap, other species within the family Sylviidae show a complex phylogenetic pattern in the presence and absence of migratory behavior as well as migratory distance (Helbig 2003). Closest relatives of Blackcaps are African Hill Babbler Pseudoalcippe abyssinica (resident, r) and Garden Warblers Sylvia borin (migratory, $\mathrm{m}$ ), but also more distantly related species show variation in migratory phenotype (such as Sardinian Warbler S. melanocephala (r), Common Whitethroat S. communis (m), Western Orphean Warbler S. hortensis (m), and Arabian Warbler S. leucomelaena $(\mathrm{r})$ ). This family-level variation in migratory behavior has allowed researchers to study phenotype-genotype associations between closely related species on different phylogenetic scales (Fig. 7.1d), e.g., de novo identified candidate loci for migratory traits can be tested for the presence or absence of a general pattern across migratory phenotypes on various phylogenetic scales (Helbig 2003; Pulido 2007; Voelker and Light 2011).

What remains controversial is the history (which state was ancestral? see Fig. 7.1d, e) and geographic origins (the tropics or the temperate region?) of these transitions. In the present day, most species winter in the tropics and migrate to temperate regions (Berthold 2001), but the remaining question concerns geographic ancestry: Did this pattern arise from shifts of breeding ranges in the tropical regions north or wintering grounds in the temperate region south (sometimes referred to as 
southern- vs. northern-home hypotheses; Fig. 7.1a-c) (Salewski and Bruderer 2007)? Recognizing this difference is relevant, because these alternate scenarios have implications for understanding evolutionary and demographic histories of many species. This topic is also interesting in terms of comprehending selection pressures behind transitions between migratory and sedentary states.

Overall, the southern-home hypothesis (i.e., assuming present-day nonbreeding sites as ancestral) has received the most support for migration patterns as we know them today (e.g., Rappole 1995; Berthold 2001): This scenario derives from the observation that seasonal abundances of resources like insects are high in the north and day length is longer. Accordingly, birds may be able to raise more offspring than their counterparts in the tropics. While the tropics would seem to provide these resources year round, there is a considerable amount of competition here that may have favored the expansion north for some populations, while others remained in the tropics. In support of this hypothesis, the center of diversity for many families - especially in North America - is in the tropics (see Brown 2014 for overview). Temperate regions have likely been affected by glacial cycles for millions of years (e.g., Hewitt 1999, 2000), and with every glacial retreat, we see evolution of migration. During these cycles, regions at higher latitudes get covered by ice sheets, which produced range contractions of birds around southern areas. As glaciers retreat, birds expand their ranges north again. A recent study consequently suggests glaciation as adaptive switch between migratory and sedentary behaviors over multiple such oscillations (Zink and Gardner 2017).

Results from several research angles provide support for these intuitive ideas (e.g., Cox 1968; Rappole and Jones 2002; Helbig 2003), including the observation above that the center of diversity for many groups is in the tropics. Many migrants have evolved from forms that originated in the tropics. What remains controversial is whether southern-home birds were resident or already migratory. The traditional view is that they were often sedentary (explicitly or implicitly) or partially migratory (e.g., Berthold 1999). But it may also be that environmental gradients associated with elevation may actually have allowed or even favored the persistence (or existence-if support for this idea accumulates) of migratory populations in southern latitudes. Consequently, it is important to distinguish between the origin of lineages and their current distribution (shaped by glaciation and ecological divergence) and the origin of the migratory behavior that may change within lineages.

Despite the intuitive potential of the southern-home hypothesis, many of the arguments are ambiguous or can be interpreted differently. For example, the center of diversity does not necessarily reflect the center of origin (e.g., Zink 2002), and the phylogenetic origin of a species does not necessarily have to coincide with the evolution of the behavior under study (Zink 2002; Salewski and Bruderer 2007; Bell 2005). In accordance with these arguments, several examples of recent work have provided strong support for the northern-home hypothesis. Winger et al. (2014) used a phylogenetic modeling approach, i.e., ranges of extant species and their evolutionary relationships, to infer geographic and demographic ancestry in the New World emberizoids, a very familiar group found in the Americas, comprising around 823 species, 120 of which are migratory. Their results suggest that migrants were more than twice as likely to evolve out of North America than the tropics, 
supporting the northern-home hypothesis - at least for this group of birds. Winger et al. (2014) further argue the transition from residency was facilitated by migration and species that are now resident in the tropics (in fact most of that focal family) have lost the ability to migrate. The authors conclude this represented a transition between residency in both north and south, i.e., birds may have started out moving south for the winter, but eventually all of them stayed. The northern-home scenario finds further support by a study in the Parulidae (Winger et al. 2012) as well as using molecular phylogenies across the complete bird tree of life (Rolland et al. 2014).

However, there is still controversy on this topic. Zink and Gardner (2017) criticize the model (in Winger et al. 2014) for not accounting for unequal living conditions at different latitudinal regions. In their view, it is crucial to take this covariate into account, as in the context of glacial oscillations, it seems very unlikely that living conditions were evenly distributed across latitudes. The authors advise to focus on using ranges at glacial maxima rather than phylogenetic reconstructions to understand the evolutionary history of migration, because range shifts occur more frequently than speciation events. Zink and Gardner (2017) conclude that migration promoted colonization of North America from the tropics. Continuously refined modeling approaches as well as advances in sequencing and tracking technologies will hopefully allow us to address these questions with much higher resolution (such as sketched in Fig. 7.1e). How these new tools can provide new and previously inaccessible insight to understand these evolutionary processes has been exemplified in a recent study on monarch butterflies Danaus plexippus with their iconic and impressive trans-generational migratory cycle (Zhan et al. 2014). Here the authors made use of high-throughput whole-genome re-sequencing data to characterize both the demography and geographical origin of migratory behavior in the monarch butterfly. Results from this study showed that ancestral populations of monarchs did not initially disperse out of Central or South but North America. Similar datasets for birds between and within different lineages will add a new level of understanding on the evolution of migration in birds.

\subsection{Regulation}

But how is this complex behavior regulated, integrated, and coordinated? Here it is important to realize that different bird species may use different migratory strategies. Most obviously, birds that migrate during the day and in flocks will face very different challenges when compared with songbirds that migrate at night and on their own. Juvenile day migrating birds may just follow their parents or other conspecifics on their first migratory journey and learn en route. This has been suggested for White Storks Ciconia ciconia (e.g., Schüz 1950; Chernetsov et al. 2004) and various species of North American waterfowl (Hochbaum 1955). This will not be possible for juvenile night-migrating songbirds like the Eurasian Blackcap we described above and many common songbirds in the temperate region like American Goldfinches Spinus tristis or European Robins Erithacus rubecula. Advances in tracking 
technology, including new GPS tags that transmit signals to the International Space Station and small archival tags that record light, are enabling researchers to track these birds on migration, providing fine-scale details about their migration and beginning to allow us to directly test hypotheses concerning the regulation of migratory behavior.

\subsubsection{Variation in Migratory Strategy}

Among migratory species, differences in how they orient on migration are especially prominent and related to the availability of reference systems. For example, flocking day migrants (particularly juvenile birds) likely follow the leader and use guiding as orientation strategy (Schüz 1943, 1951). With respect to compass references, the only ubiquitous reference system birds can use for orientation is the Earth's magnetic field (Wiltschko and Merkel 1966; Wiltschko and Wiltschko 1972). Additional celestial cues that can be used for orientation depend on time of day of the migratory journey and respective presence of the celestial cue. Day migrants can use the sun, while night-migrating songbirds may rely more on the stars and connected sunset cues such as the polarization pattern during nights (e.g., Wiltschko et al. 1987; Phillips and Moore 1992; Cochran et al. 2004). Experienced day migrants likely also make use of large-scale landmarks such as coastlines on a larger scale, but also more locally learned landmarks that can be used for fine-tuned navigation during the homing phase close to their final goal (i.e., breeding and wintering location, respectively), allowing for an additional layer of guidance and increased accuracy. This is not possible for first-time night-migrating songbirds that have to rely exclusively on inherited information. This arguably makes songbird migration more intriguing, especially given the fact that most birds return to the same territory year after year and based only on their genetic makeup.

\subsubsection{Migratory Traits Are Inherited}

Work with the Eurasian Blackcap beginning in the 1980s provided us with a considerable amount of information on the inheritance of migratory traits. For example, selection and cross-breeding experiments in this species have shown that migratory traits like distance (Berthold and Querner 1981) and direction (Helbig 1991, 1996; Berthold et al. 1992) are genetically encoded and (under strong artificial selection) have the potential to drastically change within a few generations. This is impressively illustrated by a selective breeding experiment on Blackcaps from a partially migratory population, i.e., a population where birds that migrate and resident birds co-occur. Here appropriate selection pressure resulted in almost complete resident/migratory individuals within three to six generations (Berthold et al. 1990), highlighting the important role of genetic factors in determining the 
migratory state. Displacement experiments provide further support that migratory traits are largely genetically determined in night migrants like songbirds (e.g., Perdeck 1958; Chernetsov et al. 2008). The classical displacement experiment by Perdeck beautifully illustrates different migratory strategies for adults (specifically: birds that have successfully completed the migratory journey to their wintering goals and back at least once and thus could have learned landmarks on the way) and juvenile birds on their first migratory journey heading to an area they have never been to before. The study is based on ringing recoveries of more than 10,000 ringed starlings (1/3 adults, $2 / 3$ juveniles) and reveals that only experienced adults were able to compensate for the displacement and could actively navigate to their original wintering area. In contrast, inexperienced juveniles followed an innate clock and compass strategy (also called vector navigation), namely, sticking to an inherited program that told them when to leave the breeding grounds and how long to fly along an inherited migratory direction (Perdeck 1958). Some natural scenarios in the wild provide additional support, e.g., the Common Cuckoo Cuculus canorus, whose offspring never interacts with its parents, and still they know how to migrate to Sub-Saharan Africa.

Heritability estimates for migratory traits based on quantitative genetics assessment (disentangling the relative contribution of genetic variation and environment in explaining the variation of phenotypic traits) are moderately high; they vary depending on species and traits in focus (Pulido and Berthold 2003; Pulido 2007). As an example, heritability values in Blackcaps for timing of (autumn) migration range between 0.34 and 0.45 (Berthold and Pulido 1994; Pulido and Berthold 2010). Little is known on natural trait variation in wild populations, but given advances in tracking technology, these estimates may soon become much more accessible; in general, heritability estimates from quantified behavior of captive migrants seem to be comparable to heritabilities in the wild (Pulido and Berthold 2003).

\subsubsection{Underlying Genetic Architecture: Simple and Common?}

In addition to estimates of heritability for focal traits like orientation or timing of migration, cross-breeding experiments of Blackcaps also provide insight into the mode of inheritance. Specifically, studies focusing on the orientation preference of crossbred offspring from parental groups of Blackcaps from either side of the Central European migratory divide (i.e., the German breeders mentioned above that migrate either southeast or southwest) suggest an intermediate or additive mode of inheritance in this species. Orientation phenotype here was assessed via orientation cage experiments, where birds are placed in a circular cage that is lined with scratchsensitive paper and tested for their migratory orientation. Scratches are quantified, and results suggest that directional preference of these birds is in very well accordance with the actual migratory direction of conspecifics in the wild that is 
quantified. Crossbred offspring (reared isolated from their parents to prevent any learning component from influencing the phenotype) in the first generation $\left(\mathrm{F}_{1}\right)$ exhibit a migratory direction intermediate to the parental phenotypes when tested in orientation cage experiments. Importantly, the orientation phenotype further segregates in the second generation $\left(\mathrm{F}_{2}\right)$. Specifically, the overall variance increases, but orientation preferences still cluster around both the parental and intermediate directions. This phenotype pattern suggests a simple genetic basis, i.e., only few genes with large effects influencing variability of this trait (Helbig 1991, 1996).

However, the number of examples investigating the genetics of migratory orientation is limited, and it is important to realize that different species may use different strategies and could exploit different processing cascades. The scenario in flycatchers (European Pied Ficedula hypoleuca and Collared F. albicollis), for example, suggests a different mode of inheritance. There are two species of flycatchers that breed next to one another in Central Europe and are believed to take different routes on migration, one going southwest to western Africa and the other southeast to eastern Africa (further south than the Blackcaps described above). Instead of using orientation experiments like in the Blackcap study, the orientation of these flycatchers is based on stable isotope signatures (Marra et al. 1998; Hobson 1999), which are used as a proxy for wintering location. Specifically this "signature" is coded in their feathers, reflecting the chemical composition of stable isotopes that is unique to the area where the bird resides during the time of feather growths, which in this species was on the wintering grounds. Feathers are particularly useful for stable isotope analyses as for most species they grow during a clearly defined and relatively short period of molt and then (in contrast to other tissue like claw or organs that have a higher turnover rate) become metabolically inert. In consequence, by plucking a feather of a flycatcher returning to its breeding grounds, the stable isotope signature it carries can be used as proxy to trace back its whereabouts during winter.

Interestingly and in contrast to the Blackcap with an intermediate phenotype, data from these flycatchers suggests genes controlling their migratory orientation are dominant, with hybrids between the two species wintering in the same location as European Pied Flycatcher (Veen et al. 2007). Further support for dominance of one migratory direction over the other comes from hybrids between Great Reed Warbler Acrocephalus arundinaceus and Clamorous Reed Warbler A. stentoreus, where again hybrids appear to follow the migratory orientation of Great Reed Warblers (Yohannes et al. 2011). These conflicting results on the phenotypic level call for caution in generalizing on the hypothesis of one common genetic basis for migratory orientation across species. 


\subsubsection{Marker-Based Approaches: Candidate Genes for Migration}

Building on results from quantitative genetic analyses, orientation cages, and stable isotopes and benefitting from increasingly advanced molecular tools for non-model organisms, more recent work has started to focus on identifying actual genes that may control variability of migratory traits. One popular approach is the use of candidate genes to screen for signatures of selection for a focal trait. Candidate genes are often identified in model organisms (e.g., fruit flies Drosophila or Arabidopsis, weedy flowering plants from the mustard family) that may have a function related to the trait of interest, in this case migration. The use of candidate genes rests on the assumption that genes that have been shown to influence the expression of a certain phenotype might potentially influence a similar phenotype in other animals (Long 2001). Once a candidate has been identified, researchers go out into natural populations and screen them for variation at the gene that may in turn explain variation in the trait of interest. Again, here we focus on migration.

One series of studies focused on variation (allele frequencies) at a variable genomic region within the Clock gene, a key player entraining the daily rhythm (night/dark cycle) in many organisms. Variation at this focal genomic region was quantified and correlated with various photoperiod-entrained phenotypes, specifically latitudinal variation, timing of breeding, molt, and migration (i.e., correlated timing traits throughout the annual cycle). In brief, several of these studies suggest a regulatory role of Clock on timing and migratory phenotypes (specifically association with timing of migration in fish, O'Malley and Banks 2008; latitudinal clines in Eurasian Blue Tits, Johnsen et al. 2007; breeding phenology in Eurasian Blue Tits, Liedvogel et al. 2009, and Barn Swallows, Caprioli et al. 2012; timing of molt in Barn Swallows, Saino et al. 2013; migratory phenotypes both across and within populations, Peterson et al. 2013; Saino et al. 2015; timing of migration tracked by advanced technology for phenotype assessment, i.e., light-level geolocators in Barn Swallows, Bazzi et al. 2015), but results both within and across populations of different taxa are inconsistent and prohibit from drawing general conclusions (e.g., no correlation found for latitudinal clines in Bluethroats Luscinia svecica, Johnsen et al. 2007; Barn Swallows, Dor et al. 2011; Tachycineta swallows, Dor et al. 2012; breeding phenology, Liedvogel and Sheldon 2010, and Barn Swallows, Dor et al. 2011; migratory phenotypes in Blackcaps, Müller et al. 2011). Another candidate gene studied in the context of migration genetics is ADCYAP1, specifically length variation in one microsatellite (Müller et al. 2011). Studies in Blackcaps suggest a correlation of longer alleles associated with higher migratory activity in caged migrants as well as longer distances traveled by wild birds (Müller et al. 2011; Mettler et al. 2015). But similarly to studies focusing on Clock, results from studies on ADCYAP1 lack consistency across species (e.g., Peterson et al. 2013 in the genus Junco) in order to confirm its putative function regulating migratory behavior.

In conclusion, though candidate-gene analyses may provide important insight into the regulation of behavioral traits, this approach comes with a number of 
limitations and is-especially in the context of migratory behavior-clearly restricted by our lack of knowledge on the genetic architecture of this fascinating phenotype and consequently the number of candidate genes for assumed and predefined candidate traits (Liedvogel et al. 2011; Delmore and Liedvogel 2016). This skepticism is further emphasized by a recent study screening whole-genome data of migratory and non-migratory bird species for the presence or lack of consistency in genetic variation across a set of 25 hypothesized candidate genes for migratory traits (Lugo Ramos et al. 2017). This study fails to detect a signal for migratory phenotype using different approaches and in conclusion questions the applicability of candidate-gene approaches to understand the genetic architecture of migratory behavior (Lugo Ramos et al. 2017).

\subsubsection{Enhancing Scale and Resolution: Genome-Wide Approaches}

Recent advances in the field of genomics are allowing us to expand beyond candidate genes. Of primary importance was the development of high-throughput sequencing techniques where nearly all the DNA from a single individual can be sequenced quickly and relatively cheaply, allowing researchers who work with non-model organisms (including most of the migratory animals on Earth) to obtain genome-wide data (i.e., not simply focus on a target region such as a single candidate gene but the entire genome; Fig. 7.2) for their species. In essence, these technologies are allowing researchers to overcome the limitation of possibly not being able to pick the right gene candidates, as has been exemplified by identifying the underlying genetics contributing to beak shape among Darwin's finches (Lamichhaney et al. 2015). This is especially true for birds, where only few drops of blood are needed to extract DNA with high enough quantity and quality to generate thousands of sequence stretches allowing for de novo assembling its entire genome. Having a well-characterized reference genome of your focal evolutionary model at hand enables us to go ahead and de novo identify candidate genomic regions that may be involved in shaping migratory phenotypes.

The importance of applying high-throughput sequencing to questions of migration and its genetic basis has been exemplified in the Swainson's Thrush Catharus ustulatus (Delmore et al. 2016). This species includes two subspecies groups that hybridize in western North America and migrate along different routes. One subspecies hugs the coast of western North American to winter in Central America, and the other flies through the central United States and over the Gulf of Mexico to winter in South America. Previous work in the system using archival tags that record light intensity (geolocators) showed that hybrids take intermediate routes compared to their parents, leading them over ecological barriers like mountain chains that pure forms avoid (Delmore and Irwin 2014). Using high-throughput sequencing techniques, this variation in phenotype was linked to variation on the genome level. This 
approach enables the de novo characterization of genomic differentiation between migratory phenotypes and in this study allowed researchers to narrow in on a relatively small region of the genome (located on chromosome 4, covering $\sim 60$ genes including the previously discussed candidate gene Clock) that may govern this behavior (Delmore et al. 2016).

A comparable study investigating the genetic architecture of migratory orientation (phenotype assessment here was based on stable isotope signatures as a proxy for wintering location rather than geolocator tracks) was conducted in a songbird species with a Eurasian breeding range, the Willow Warbler Phylloscopus trochilus. Two subspecies of Willow Warbler form a migratory divide in central Scandinavia, and whole-genome re-sequencing data and SNP-chip data comparing these groups confirmed overall extremely high genetic similarity with significant differences restricted to two regions in the genome (on chromosomes 1 and 5) (Lundberg et al. 2017). The low level of genetic differentiation in Willow Warblers is in contrast to much more elevated differentiation levels in the Swainson's Thrush (Ruegg et al. 2014; Delmore et al. 2015a, 2016) indicative for early (low) or later stages of divergence (high levels of differentiation). Relatively few additional studies on this line of investigation are available, although work with the Barn Swallow (von Rönn et al. 2016; Safran et al. 2016; Scordato et al. 2017) has been conducted. In contrast to Swainson's Thrushes and Willow Warblers, Barn Swallows migrate during the day and in flocks. Accordingly, and as mentioned above, they may use different cues for migration, and there may be less of a genetic component to this behavior.

One surprising result from the limited work that has been conducted to date is that the de novo identified regions showing highest levels of differentiation with migratory orientation in the thrush and warbler are located in different regions of the genome. In addition, while the Clock gene may be involved in the orientation of thrushes, it was only one among many other genes that showed an association with migration in this system, and no such link was found in the Willow Warbler, suggesting there is no consistent pattern linking migratory traits with candidate genes or de novo identified regions across species. In summary, the lack of a consistent pattern across species (not only of marker-based but also using wholegenome approaches) calls for skepticism about the aforementioned hypothesized common and simple genetic basis of migratory traits. Consequently, we want to close this section with the interim conclusion that the genomic architecture of migratory traits may well be simple—but not necessarily common, i.e., shared across groups or species.

\subsection{Population Differentiation and Speciation}

Thus far we have discussed recent work on the origins of migratory behavior and how this is regulated. In this last section, we will focus on the role differences in migratory phenotype could play in speciation, the process by which one species evolves into two. This topic relates mostly to songbirds, the most diverse order of 
birds comprising more than 6000 species (i.e., half of all bird species). Among songbirds, $40 \%$ are migratory, many of which form migratory divides. Intuitively one might expect that migration would actually prevent speciation from occurring, as at the most basic level, this behavior increases movement both in the form of natal dispersal (where juvenile songbirds breed in locations distant from where they were born) and the annual movement between breeding and wintering grounds. There is some support for this idea. For example, Belliure et al. (2000) showed a negative relationship between dispersal and subspecies richness. Nevertheless, accumulating evidence suggests that migration may play a more important role in the formation of species.

There are two main ways differences in the migratory routes taken by songbirds can help maintain species boundaries: First, the use of different routes could cause populations to arrive on their breeding grounds at different times. If they mate assortatively based on arrival time, this difference will prevent mixed pairs from forming (i.e., pairs between individuals that migrate along different routes and following different timing schedules) and help maintain species boundaries (Irwin and Irwin 2005). Consider, for example, if one species arrives before the other and pairs immediately, there will only be birds following the same timing regime around to mate with. This scenario, where individuals are prevented from breeding with one another, is considered a pre-mating barrier to blending between species.

Bearhop et al. (2005) conducted one of the most elegant studies of this hypothesis in European Blackcaps. This work was conducted using the Blackcap with populations that migrate northwest to the UK or southwest to Spain and Portugal. Similar to work discussed above for flycatchers, Bearhop et al. used stable isotopes (of claw tissue in this case as Blackcaps do not have a complete molt on their wintering grounds, which would allow to use feathers) to identify the wintering grounds of Blackcaps breeding in Central Europe. Bearhop et al. noted that individuals from the northwestern population arrived earlier on the breeding grounds and mated assortatively based on the location of their wintering grounds. There are a few other studies supporting the role differences in arrival time that could play in maintaining species boundaries (e.g., Friesen et al. 2007 in a study focused on Band-rumped Storm Petrels Oceanodroma castro that breed in the Atlantic and Pacific Oceans). Nevertheless, it should be noted that there is normally some degree of overlap in arrival time between populations and only a few non-assortative pairs are needed to break down this barrier.

A more convincing way migration could contribute to speciation concerns the fitness of offspring produced by interbreeding between populations or (sub)species (i.e., hybrids) at these divides. As we have already discussed, migratory routes are largely genetically determined in songbirds. These routes are often optimized to take birds around large unsuitable areas that form ecological barriers (such as long stretches of deserts or water bodies that require nonstop flights and mountains). Accordingly, it has been predicted that (depending on the mode of inheritance) (1) hybrids at these divides use intermediate migratory routes, because they will have genes from both groups, and (2) that these routes will be inferior to those optimized routes of pure, parental forms as they will bring hybrids over the unsuitable areas that 
pure forms avoid (Helbig 1991; Irwin and Irwin 2005). Under this scenario, hybrids will likely survive at lower rates preventing gene flow between populations from breaking down species boundaries. Under this scenario, migration is considered a post-mating barrier as mating between populations has already occurred to produce hybrids.

Early work with orientation cages supported this hypothesis (e.g., Helbig 1991, 1996) but was evaluated more recently using archival tags (light-level geolocators) that record light intensity (Delmore and Irwin 2014). These devices were described above and provide researchers with year-round information on the location of birds, their breeding, stopover and wintering sites that are all captured along with movement days. This work was mentioned above, focusing on the Swainson's Thrush that forms a migratory divide in western North America. Hybrids in this system were fitted with geolocators and shown to take intermediate routes that brought them over several unsuitable areas, including deserts in the southwestern United States, the Coast, Cascade and Rocky Mountains (Delmore and Irwin 2014), confirming orientation cage experiments with the Blackcap. There is complimentary data from this system showing that hybrids are less fit than parental forms (e.g., population densities are lower at the center of the hybrid zone compared to the range of parental forms), supporting the idea that these intermediate routes reduce the fitness of hybrids and help maintain boundaries in this system.

All of the work we have discussed in the context of population differentiation and speciation thus far has been conducted in single systems. A few studies have begun to examine the role migration plays in speciation on a broader scale. For example, Møller et al. (2011) used data on ringing recoveries to identify migratory divides between passerines in Europe. Over one quarter of all species, they identified formed divides, and many showed evidence of local adaptation. In other words, they appear to have adapted to their local environment, and this fact likely helps maintain species boundaries. Rohwer and Irwin (2011) took this one step further, identifying 12 wellstudied hybrid zones between birds in North America and showing that among these 12, 8 form migratory divides with substantial barriers (e.g., lower densities within hybrid zones). These studies established the plausibility that migratory divides could promote reproductive isolation on a broad scale but did not include a rigorous statistical analysis or a quantitative measure of reproductive isolation.

One recent attempt to fill this gap was conducted by Delmore et al. (2015b). In this study, morphology, color, and song for species pairs of North American songbirds that do or do not form divides were characterized using museum specimens and song databases. They used differences in these traits as a measure of species boundaries or isolation, assuming that the more isolated a pair is, the greater the differences in these traits. The underlying rationale was that, if migration does play a role in speciation, those pairs that form divides should exhibit greater differences in morphology, color, and/or song. But in contrary to this prediction, the authors found differences in morphology, color, and song which were greater in pairs that do not form migratory divides. This finding likely relates to a process called differentiation fusion, where species pairs that do not differ in migratory orientation were simply lost (blended together) and the only pairs that do not form 
divides that still exist are those that differed in another trait (morphology, color, and/or song). In other words, if a pair did not differ in migration, they had to differ in another trait to avoid blending into a single species. Under this scenario, differences in migration are still important in songbird speciation, though through a different process.

The comparative analyses discussed above suggest migration may play a primary role in maintaining species boundaries between songbirds. As a final note, and to place this idea in an even broader context, it is important to realize that recent work in the speciation literature has more generally advocated the importance of barriers deriving from ecological differences (versus those that related to intrinsic differences between species including things like genetic incompatibilities, Schluter 2001; Rundle and Nosil 2005; Nosil 2012; Butlin et al. 2017). Among birds, there has been even more emphasis placed on post-mating barriers (those that act after mating) as hybrids are very common in this group suggesting pre-mating barriers are not complete (Grant and Grant 1992; Price and Bouvier 2002; Rabosky and Matute 2013). Migration fills this role very well, as differences in migration are ecological in nature, and while they can act before mating (e.g., through differences in arrival time and subsequent assortative mating), they are likely more powerful after mating, reducing the fitness of hybrids that are forced to face huge barriers on migration.

Acknowledgments We thank Javier Pérez-Tris and Juan Carlos Illera for thoughts and discussion of the manuscript and Derek Caetano-Anolles for figure illustrations. Funding was provided by the Max Planck Society through a Max Planck Research Group grant.

\section{References}

Alerstam T, Hedenström A, Akesson S (2003) Long-distance migration: evolution and determinants. Oikos 103:247-260

Bazzi G et al (2015) Clock gene polymorphism and scheduling of migration: a geolocator study of the barn swallow Hirundo rustica. Sci Rep 5:12443. https://doi.org/10.1038/srep12443

Bearhop S et al (2005) Assortative mating as a mechanism for rapid evolution of a migratory divide. Science 310:502-504. https://doi.org/10.1126/science.1115661

Bell C (2005) The origin and development of bird migration: comments on Rappole and Jones, and an alternative evolutionary model. Ardea 93:115-123

Belliure J, Sorci G, Møller AP, Clobert J (2000) Dispersal distances predict subspecies richness in birds. J Evol Biol 13:480-487

Berthold P (1999) A comprehensive theory for the evolution, control and adaptability of avian migration. In: Adams NJ, Slotow RH (eds) Proceedings of the 22nd international ornithological congress, Durban. Ostrich 70(1):1-11

Berthold P (2001) Bird migration: a general survey, 2nd edn. Oxford University Press, Oxford

Berthold P, Pulido F (1994) Heritability of migratory activity in a natural bird population. Proc R Soc B Biol Sci 257:311-315. https://doi.org/10.1098/rspb.1994.0131

Berthold P, Querner U (1981) Genetic basis of migratory behavior in European warblers. Science 212:77-79. https://doi.org/10.1126/science.212.4490.77 
Berthold P, Mohr G, Querner U (1990) Steuerung und potentielle Evolutionsgeschwindigkeit des obligaten Teilzieherverhaltens: Ergebnisse eines Zweiweg-Selektionsexperiments mit der Mönchsgrasmücke (Sylvia atricapilla). J Ornithol 131:33-45. https://doi.org/10.1007/BF01644896

Berthold P et al (1992) Rapid microevolution of migratory behaviour in a wild bird species. Nature 360:668-670. https://doi.org/10.1038/360668a0

Brown JH (2014) Why are there so many species in the tropics? J Biogeogr 41:8-22. https://doi.org/ $10.1111 /$ jbi. 12228

Butlin R et al, The Marie Curie Speciation Network (2017) What do we need to know about speciation? TREE 27:27-39. https://doi.org/10.1016/j.tree.2011.09.002

Caprioli $\mathrm{M}$ et al (2012) Clock gene variation is associated with breeding phenology and maybe under directional selection in the migratory barn swallow. PLoS One 7(4):e35140. https://doi. org/10.1371/journal.pone.0035140

Chernetsov N, Berthold P, Querner U (2004) Migratory orientation of first-year white storks (Ciconia ciconia): inherited information and social interactions. J Exp Biol 207:937-943

Chernetsov N, Kishkinev D, Mouritsen H (2008) A long-distance avian migrant compensates for longitudinal displacement during spring migration. Curr Biol 18:188-190. https://doi.org/10. 1016/j.cub.2008.01.018

Cochran WW, Mouritsen H, Wikelski M (2004) Migrating songbirds recalibrate their magnetic compass daily from twilight cues. Science 304:405-408

Cox GW (1968) The role of competition in the evolution of migration. Evolution 22:180-192. https://doi.org/10.1111/j.1558-5646.1968.tb03461.x

Delmore KE, Irwin DE (2014) Hybrid songbirds employ intermediate routes in a migratory divide. Ecol Lett 17:1211-1218. https://doi.org/10.1111/ele.12326

Delmore KE, Liedvogel M (2016) Investigating factors that generate and maintain variation in migratory orientation: a primer for recent and future work. Front Behav Neurosci 10:3. https://doi.org/10.3389/ fnbeh.2016.00003

Delmore KE et al (2015a) Genomic analysis of a migratory divide reveals candidate genes for migration and implicates selective sweeps in generating islands of differentiation. Mol Ecol 24:1873

Delmore KE, Kenyon HL, Germain RR, Irwin DE (2015b) Phenotypic divergence during speciation is inversely associated with differences in seasonal migration. Proc R Soc B Biol Sci 282:20151921

Delmore KE et al (2016) The genetics of seasonal migration and plumage color. Curr Biol 26: R1155-R1157

Dor R et al (2011) Low variation in the polymorphic Clock gene poly-Q region despite population genetic structure across barn swallow (Hirundo rustica) populations. PLoS One 6(12):e28843. https://doi.org/10.1371/journal.pone.0028843

Dor R et al (2012) Clock gene variation in Tachycineta swallows. Ecol Evol 2:95-105. https://doi. org/10.1002/ece 3.73

Friesen VL, Smith AL, Gómez-Díaz E, Bolton M, Furness RW, González-Solís J, Monteiro LR (2007) Sympatric speciation by allochrony in a seabird. PNAS 104:18589-18594. https://doi. org/10.1073/pnas.0700446104

Grant PR, Grant BR (1992) Hybridization of bird species. Science 256:193-197. https://doi.org/10. $1126 /$ science. 256.5054 .193

Helbig AJ (1991) Inheritance of migratory direction in a bird species: a cross-breeding experiment with SE- and SW-migrating Blackcaps (Sylvia atricapilla). Behav Ecol Sociobiol 28:9-12. https://doi.org/10.1007/BF00172133

Helbig A (1996) Genetic basis, mode of inheritance and evolutionary changes of migratory directions in palaearctic warblers (Aves: Sylviidae). J Exp Biol 199:49-55

Helbig A (2003) Evolution of bird migration: a phylogenetic and biogeographic perspective. In: Berthold P, Gwinner E, Sonnenschein E (eds) Avian migration. Springer, Berlin, pp 3-20

Hewitt GM (1999) Post-glacial re-colonization of European biota. Biol J 68:87-112. https://doi.org/ 10.1111/j.1095-8312.1999.tb01160.x 
Hewitt GM (2000) The genetic legacy of the Quaternatry ice ages. Nature 405:907-913. https://doi. org/10.1038/35016000

Hobson KA (1999) Tracing origins and migration of wildlife using stable isotopes: a review. Oecologia 120:314-326

Hochbaum HA (1955) Travels and traditions of waterfowl. University of Minnesota Press, Minneapolis, $\mathrm{MN}$

Irwin DE, Irwin JH (2005) Siberian migratory divides: the role of seasonal migration in speciation. In: Greenberg R, Marra PP (eds) Birds of two worlds: the ecology and evolution of migration. Johns Hopkins University Press, Baltimore, MD, pp 27-40

Johnsen A et al (2007) Avian Clock gene polymorphism: evidence for a latitudinal cline in allele frequencies. Mol Ecol 16:4867-4880

Lamichhaney S et al (2015) Evolution of Darwin's finches and their beaks revealed by genome sequencing. Nature 518:371-375. https://doi.org/10.1038/nature14181

Liedvogel M, Sheldon BC (2010) Low variability and absence of phenotypic correlates of Clock gene variation in the great tit. J Avian Biol 41:543-550

Liedvogel M, Szulkin M, Knowles SCL, Wood M, Sheldon BC (2009) Phenotypic correlates of variation at the Clock gene in a wild blue tit population: evidence for a role in seasonal timing of reproduction. Mol Ecol 18:2444-2245

Liedvogel M, Åkesson S, Bensch S (2011) The genetics of migration on the move. TREE 26:561-569

Long A (2001) Candidate gene. Encycl Gen:263-264

Lugo Ramos JS, Delmore KE, Liedvogel M (2017) Candidate genes for migration do not distinguish migratory and non-migratory birds. J Comp Physiol A 203:383-397. https://doi.org/10.1007/ s00359-017-1184-6

Lundberg $\mathrm{M}$ et al (2017) Genetic differences between willow warbler migratory phenotypes are few and cluster in large haplotype blocks. Evol Lett 1:155-168. https://doi.org/10.1002/evl3.15

Marra PP, Hobson KA, Holmes RT (1998) Linking winter and summer events in a migratory bird by using stable-carbon isotopes. Science 282:1884-1886. https://doi.org/10.1126/science.282. 5395.1884

Mettler R, Segelbacher G, Schaefer HM (2015) Interactions between a candidate gene for migration (ADCYAP1), morphology and sex predict spring arrival in Blackcap populations. PLoS One 10 (12):e0144587. https://doi.org/10.1371/journal.pone.0144587

Møller AP, Garamszegi LZ, Peralta-Sánchez JM, Soler JJ (2011) Migratory divides and their consequences for dispersal, population size and parasite-host interactions. J Evol Biol 24:1744-1755. https://doi.org/10.1111/j.1420-9101.2011.02302.x

Müller JC, Pulido F, Kempenaers B (2011) Identification of a gene associated with avian migratory behaviour. Proc R Soc B Biol Sci 278:2848-2856. https://doi.org/10.1098/rspb.2010.2567

Nosil P (2012) Ecological speciation. Oxford University Press, Oxford

O'Malley KG, Banks MA (2008) A latitudinal cline in the Chinook salmon Oncorhynchus tshawytscha Clock gene: evidence for selection on PolyQ length variants. Proc R Soc B Biol Sci 275:2813-2821

Perdeck AC (1958) Two types of orientation in migrating starlings, Sturnus vulgaris L., and chaffinches, Fringilla coelebs L., as revealed by displacement experiments. Ardea 46:1-37

Peterson MP et al (2013) Variation in candidate genes CLOCK and ADCYAP1 does not consistently predict differences in migratory behavior in the songbird genus Junco. F1000Research:1-18

Phillips JB, Moore FR (1992) Calibration of the sun compass by sunset polarized light patterns in a migratory bird. Behav Ecol Sociobiol 31:189-193

Plummer KE, Siriwardena GM, Conway GJ et al (2015) Is supplementary feeding in gardens a driver of evolutionary change in a migratory bird species? Glob Chang Biol 21:4353-4363. https://doi.org/10.1111/gcb.13070

Price TD, Bouvier MM (2002) The evolution of F1 postzygotic incompatibilities in birds. Evolution 56:2083-2089. https://doi.org/10.1111/j.0014-3820.2002.tb00133.x

Pulido F (2007) The genetics and evolution of avian migration. Bioscience 57:165-174 
Pulido F, Berthold P (2003) Quantitative genetic analysis of migratory behavior. In: Berthold P, Gwinner E, Sonnenschein E (eds) Avian migration. Springer, Berlin, pp 53-77

Pulido F, Berthold P (2010) Current selection for lower migratory activity will drive the evolution of residency in a migratory bird population. Proc Natl Acad Sci U S A 107:7341-7346

Rabosky DL, Matute DR (2013) Macroevolutionary speciation rates are decoupled from the evolution of intrinsic reproductive isolation in Drosophila and birds. Proc Natl Acad Sci U S A 110:15 354-15 359. https://doi.org/10.1073/pnas.1305529110

Rappole J (1995) The ecology of migrant birds: a neotropical perspective. Smithsonian Institution Press, Washington, DC

Rappole JH, Jones P (2002) Evolution of old and new world migration systems. Ardea 90:525-537

Rohwer S, Irwin DE (2011) Molt, orientation, and avian speciation. Auk 128:419-425. https://doi. org/10.1525/auk.2011.10176

Rolland J, Condamine FL, Jiguet F, Morlon H (2014) Faster speciation and reduced extinction in the tropics contribute to the mammalian latitudinal diversity gradient. PLoS Biol 12(1): e1001775. https://doi.org/10.1371/journal.pbio.1001775

Rolshausen G, Segelbacher G, Hobson KA, Schaefer HM (2009) Contemporary evolution of reproductive isolation and phenotypic divergence in sympatry along a migratory divide. Curr Biol 19:2097-2101. https://doi.org/10.1016/j.cub.2009.10.061

Ruegg K et al (2014) A role for migration-linked genes and genomic islands in divergence of a songbird. Mol Ecol 23:4757-4769

Rundle H, Nosil P (2005) Ecological speciation. Ecol Lett 8:336-352

Safran RJ et al (2016) Genome-wide differentiation in closely related populations: the roles of selection and geographic isolation. Mol Ecol 25:3865-3883

Saino N et al (2013) Timing of molt of barn swallows is delayed in a rare Clock genotype. PeerJ 1:e17

Saino N et al (2015) Polymorphism at the Clock gene predicts phenology of long-distance migration in birds. Mol Ecol 24:1758-1773. https://doi.org/10.1111/mec.13159

Salewski V, Bruderer B (2007) The evolution of bird migration: a synthesis. Naturwissenschaften 94:268-279. https://doi.org/10.1007/s00114-006-0186-y

Schluter D (2001) Ecology and the origin of species. TREE 16:372-380

Schüz E (1943) Versuche über die Bindung des Storchs an seinen Aufzuchtsort. Vogelzug 14:137-141

Schüz E (1950) Die Früh-Auflassung ostpreussischer Jungstörche in West-Deutschland durch die Vogelwarte Rossitten 1933. Vogelwarte 15:63-78

Schüz E (1951) Überblick über die Orientierungsversuche der Vogelwarte Rossitten (jetzt: Vogelwarte Radolfzell). Proceedings of the Xth international ornithological congress, Uppsala, Sweden, pp 249-268

Scordato ESC et al (2017) Genomic variation across two barn swallow hybrid zones reveals traits associated with divergence in sympatry and allopatry. Mol Ecol 26:5676-5691. https://doi.org/ $10.1111 /$ mec. 14276

Veen $\mathrm{T}$ et al (2007) Does migration of hybrids contribute to post-zygotic isolation in flycatchers? Proc R Soc B 274:707-712. https://doi.org/10.1098/rspb.2006.0058

Voelker G, Light JE (2011) Palaeoclimatic events, dispersal and migratory losses along the Afro-European axis as drivers of biogeographic distribution in Sylvia warblers. BMC Evol Biol 11:163. https://doi.org/10.1186/1471-2148-11-163

von Rönn JA, Shafer AB, Wolf JB (2016) Disruptive selection without genome-wide evolution across a migratory divide. Mol Ecol 25:2529-2541

Wiltschko W, Merkel FW (1966) Orientierung zugunruhiger Rotkehlchen im statischen Magnetfeld. Verh Deutsche Zool Ges 59:362-367

Wiltschko W, Wiltschko R (1972) Magnetic compass of European robins. Science 176:62-64

Wiltschko W, Daum P, Fergenbauer-Kimmel A, Wiltschko R (1987) The development of the star compass in Garden Warblers, Sylvia borin. Ethology 74:285-292

Winger BM, Lovette IJ, Winkler DW (2012) Ancestry and evolution of seasonal migration in the Parulidae. Proc R Soc B 279:610-618. https://doi.org/10.1098/rspb.2011.1045 
Winger BM, Barker K, Ree RH (2014) Temperate origins of long-distance seasonal migration in New World songbirds. PNAS 111:12115-12120. https://doi.org/10.1073/pnas.1405000111

Yohannes E, Lee RW, Jochimsen MC, Hansson B (2011) Stable isotope ratios in winter-grown feathers of Great Reed Warblers Acrocephalus arundinaceus, Clamorous Reed Warblers A. stentoreus and their hybrids in a sympatric breeding population in Kazakhstan. Ibis 153:502-508

Zhan S et al (2014) The genetics of monarch butterfly migration and warning colouration. Nature 514:317-321. https://doi.org/10.1038/nature13812

Zink R (2002) Towards a framework for understanding the evolution of avian migration. J Avian Biol 33:433-436. https://doi.org/10.1034/j.1600-048X.2002.03081.x

Zink RM, Gardner AS (2017) Glaciation as a migratory switch. Sci Adv 3:e1603133

Open Access This chapter is licensed under the terms of the Creative Commons Attribution 4.0 International License (http://creativecommons.org/licenses/by/4.0/), which permits use, sharing, adaptation, distribution and reproduction in any medium or format, as long as you give appropriate credit to the original author(s) and the source, provide a link to the Creative Commons license and indicate if changes were made.

The images or other third party material in this chapter are included in the chapter's Creative Commons license, unless indicated otherwise in a credit line to the material. If material is not included in the chapter's Creative Commons license and your intended use is not permitted by statutory regulation or exceeds the permitted use, you will need to obtain permission directly from the copyright holder. 